Journal of Animal and Veterinary Advances 10 (19): 2593-2598, 2011

ISSN: $1680-5593$

(C) Medwell Journals, 2011

\title{
Isolation, Sequence Identification and Tissue Expression Profile of a Novel Sheep Gene-SERPINF1
}

\author{
${ }^{1}$ Jiang Caode and ${ }^{2}$ Liu Yonggang \\ ${ }^{1}$ School of Life Science, Southwest University, 400715 Chongqing, China \\ ${ }^{2}$ College of Animal Science and Technology, Yunnan Agricultural University, \\ 650201 Kunming, China
}

\begin{abstract}
The full-length cDNA sequences of one sheep gene, SERPINF1 was amplified using the Rapid Amplification of cDNA Ends (RACE) method based on one pig EST sequence which was highly homologous to the coding sequence of human SERPINF1 gene. Sequence prediction analysis revealed that the open reading frame of this gene encodes a protein of 416 amino acids that has high homology with the serpin peptidase inhibitor, clade $\mathrm{F}$ (alpha-2 antiplasmin, pigment epithelium derived factor), member 1 (SERPINF1) of twelve species-bovine ( $96 \%$ ), pig $(91 \%)$, human ( $88 \%)$, chimpanzee $(88 \%)$, horse ( $88 \%)$, crab-eating macaque $(87 \%)$, $\operatorname{dog}(89 \%)$, domestic guinea pig $(84 \%)$, mouse $(85 \%)$, rat $(83 \%)$, red jungle fowl $(63 \%)$ and western clawed frog $(55 \%)$ so that it can be defined as sheep SERPINF1 gene. This novel sheep gene was assigned to GeneID: 100192425. The phylogenetic analysis revealed that the sheep SERPINF1 gene has a closer genetic relationship with the SERPINF1 gene of bovine. Tissue expression analysis indicated that the sheep SERPINF1 gene is differentially expressed in detected tissues including spleen, muscle, skin, kidney, lung, liver, fat and heart. The experiment is the first to establish the primary foundation for further research on the sheep SERPINF1 gene.
\end{abstract}

Key words: Sheep, SERPINF1, RACE, tissue expression profile, sequence identification, China

\section{INTRODUCTION}

SERPINF1 is a member of the serpin family although, it does not display the serine protease inhibitory activity shown by many of the other serpin family members. The encoded protein is secreted and strongly inhibits angiogenesis. In addition this protein is a neurotrophic factor involved in neuronal differentiation in retinoblastoma cells (Gvritishvili et al., 2010; Konson et al., 2011; Ho et al., 2010; Chen et al., 2010). However, other studies have demonstrated that SERPINF1 gene was also involved in biological processes and metabolic processes such as cell proliferation, aging, kidney development, multicellular organismal development, negative regulation of angiogenesis, negative regulation of endopeptidase activity, negative regulation of epithelial cell proliferation involved in prostate gland development, negative regulation of inflammatory response, positive regulation of neurogenesis, regulation of proteolysis, response to glucocorticoid stimulus, response to retinoic acid and short-term memory (Pignolo et al., 1993; Simonovic et al., 2001; Becerra et al., 1993; Wagsater et al., 2010).

SERPINF1 gene is an important gene which has many biological functions. Until today, SERPINF1 gene has been reported in bovine, pig, human, chimpanzee, horse, crab-eating macaque, dog, domestic guinea pig, mouse, rat, red jungle fowl, western clawed frog and other animals. The sheep SERPINF1 has not been reported.

In the present experiment, the researchers will clone the full-length cDNA sequence of the sheep SERPINF1 gene and further do necessary sequence analysis and tissue expression analysis. These will establish the primary foundation of understanding this sheep gene.

\section{MATERIALS AND METHODS}

Animals and sample preparation: Five adult Yunnan local sheep were slaughtered. Spleen, muscle, skin, kidney, lung, liver, fat and heart samples were collected, frozen in liquid nitrogen and then stored at $-80^{\circ} \mathrm{C}$. The total RNA was extracted using the Total RNA Extraction Kit (Gibco, USA). These RNA samples were used to perform RACE PCR and tissue expression profile analysis.

5'- and 3'-RACE: The 5'-and 3'-RACE were performed to isolate the full-length cDNA for sheep SERPINF1 gene as the instructions of BD SMART ${ }^{\mathrm{TM}} \mathrm{RACE}$ cDNA Amplification Kit (BD science, USA). For the sheep

Corresponding Author: Liu Yonggang, College of Animal Science and Technology, Yunnan Agricultural University, 650201 Kunming, China 


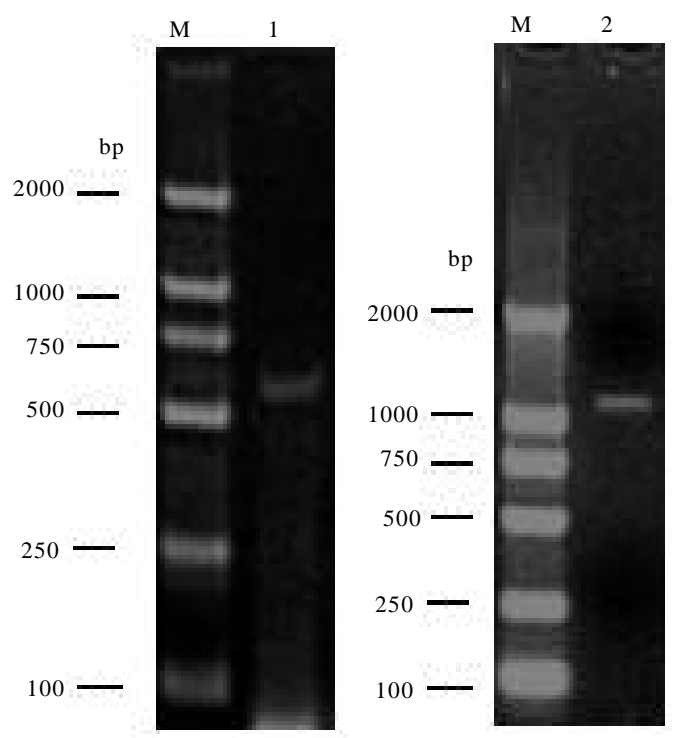

Fig. 1: RACE results for sheep SERPINF1 gene. $M$, DL2000 DNA markers 1, 5'-RACE product for SERPINF1 gene; 2, 3'-RACE product for SERPINF 1 gene

SERPINF1 gene, the Gene-Specific Primers (GSPs) were designed based on one sheep EST sequence whose sequence is highly homologous to the coding sequence of human SERPINF1 gene: EE758330. The Gene-Specific Primers (GSPs) were: 5'-RACE GSP: 5'-GCCTGCACCCA GTTGTTAATCTCCT-3', 3'-RACEGSP: 5'-CCGGGCTCT GTACTACGACCTGATC-3'. RACE touchdown PCRs were carried out with 5 cycles of $94^{\circ} \mathrm{C} / 30 \mathrm{sec}$ and $72^{\circ} \mathrm{C} / 3 \mathrm{~min}$ followed by 5 cycles of $94^{\circ} \mathrm{C} / 30 \mathrm{sec}, 67^{\circ} \mathrm{C} / 30 \mathrm{sec}$ and $72^{\circ} \mathrm{C} / 3 \mathrm{~min}$, finally with 30 cycles of $94^{\circ} \mathrm{C} / 30 \mathrm{sec}$, $67^{\circ} \mathrm{C} / 30 \mathrm{sec}, 72^{\circ} \mathrm{C} / 3 \mathrm{~min}$ to terminate reaction. The RACE PCR products were then cloned into pMD18-T vector (TaKaRa, Dalian, China) and sequenced bidirectionally with the commercial fluorometric method (SHENGGONG, Shanghai, China). At least five independent clones were sequenced for each PCR product (Fig. 1).

Semi-quantitative RT-PCR: RT-PCR for tissue expression profile analysis was performed as previously described elsewhere (Liu and Gao, 2009; Yonggang and Shizheng, 2009; Liu, 2009). The researchers selected the housekeeping gene $\beta$-actin (Accession no: NM_001009784) was performed as a positive control. The control primers used were: 5'-ATCACCATCG-GCAATG AGC-3' (forward primer1) and 5'-CCGTGTTGGCGTAGA GGT-3' (reverse primer1). The PCR product is $151 \mathrm{bp}$ in length. The following SERPINF1 gene specific primers were used to perform the RT-PCR for tissue expression profile analysis: 5'-ACATCCACG-GCACCTACA-3' (forward primer2) and 5'- AACTTTCACGGTCCTCCC-3' (reverse primer2). The PCR product is $374 \mathrm{bp}$ in length. The $25 \mu \mathrm{L}$ reaction system was: $2 \mu \mathrm{L}$ cDNA (100 ng), 5 pmoles each oligonucleotide primer (forward primer 1 and reverse primer 1 or forward primer and reverse primer2), $2.5 \mu \mathrm{L} 2 \mathrm{mmol} \mathrm{L}^{-1}$ mixed dNTPs, $2.5 \mu \mathrm{L} \mathrm{10 \times Taq} \mathrm{DNA}$ polymerase buffer, $2.5 \mu \mathrm{L} 25 \mathrm{mmol} \mathrm{L}^{-1} \mathrm{MgCl}_{2}, 1.0$ units of Taq DNA polymerase and finally add sterile water to volume $25 \mu \mathrm{L}$. The PCR program initially started with a $94^{\circ} \mathrm{C}$ denaturation for $4 \mathrm{~min}$, followed by 30 cycles of $94^{\circ} \mathrm{C} / 50 \mathrm{sec}, 54^{\circ} \mathrm{C} / 50 \mathrm{sec}, 72^{\circ} \mathrm{C} / 50 \mathrm{sec}$ then $72^{\circ} \mathrm{C}$ extension for $10 \mathrm{~min}$, finally $4^{\circ} \mathrm{C}$ to terminate the reaction.

Sequence analysis: The cDNA sequence prediction was conducted using GenScan software (http://-genes.mit. edu/GENSCAN.html). The protein prediction and analysis were performed using the conserved domain architecture retrieval tool of BLAST at the National Center for Biotechnology Information (NCBI) server (http://www. ncbi.nlm.nih.gov/BLAST) and the ClustalW software (http://www.ebi.ac.uk/clustalw).

\section{RESULTS AND DISCUSSION}

ACE results for sheep SERPINF1 gene: Through 5'RACE, one PCR product of $\sim 600$ bp was obtained. The $3^{\prime}-$ RACE product was $\sim 1.1 \mathrm{~kb}$. These products were then cloned to T-vector and sequenced. Taken together, a 1422 bp cDNA complete sequence was finally obtained.

Sequence analysis: The cDNA nucleotide sequence analysis using the BLAST software revealed that this 1422 bp cDNA sequence was not homologous to any of the known sheep genes and it was then deposited into the GenBank database (Accession number: FJ211198). The sequence prediction was carried out using the GenScan software and results showed that this $1422 \mathrm{bp}$ cDNA sequence represented one single gene which encoded 416 amino acids. The theoretical isoelectric point $(\mathrm{pI})$ and Molecular weight $(\mathrm{Mw})$ of this deduced protein were computed using the Compute $\mathrm{pI} / \mathrm{Mw}$ tool. The $\mathrm{pI}$ is 7.73 . The molecular weight of this putative protein is 45957.77 . This novel sheep gene was assigned to GeneID: 100192425. The complete cDNA sequence of this gene and the encoded amino acids were shown in Fig. 2.

Further BLAST analysis of this deduced protein revealed that this protein has high homology with the serpin peptidase inhibitor, clade $\mathrm{F}$ (alpha-2 antiplasmin, pigment epithelium derived factor), member 1 (SERPINF1) of twelve species-bovine (96\%), pig (91\%), human (88\%), chimpanzee $(88 \%)$, horse $(88 \%)$, crab-eating macaque $(87 \%)$, dog $(89 \%)$, domestic guinea pig (84\%), mouse $(85 \%)$, rat $(83 \%)$, red jungle fowl $(63 \%)$ and western clawed frog (55\%) (Fig. 3). 


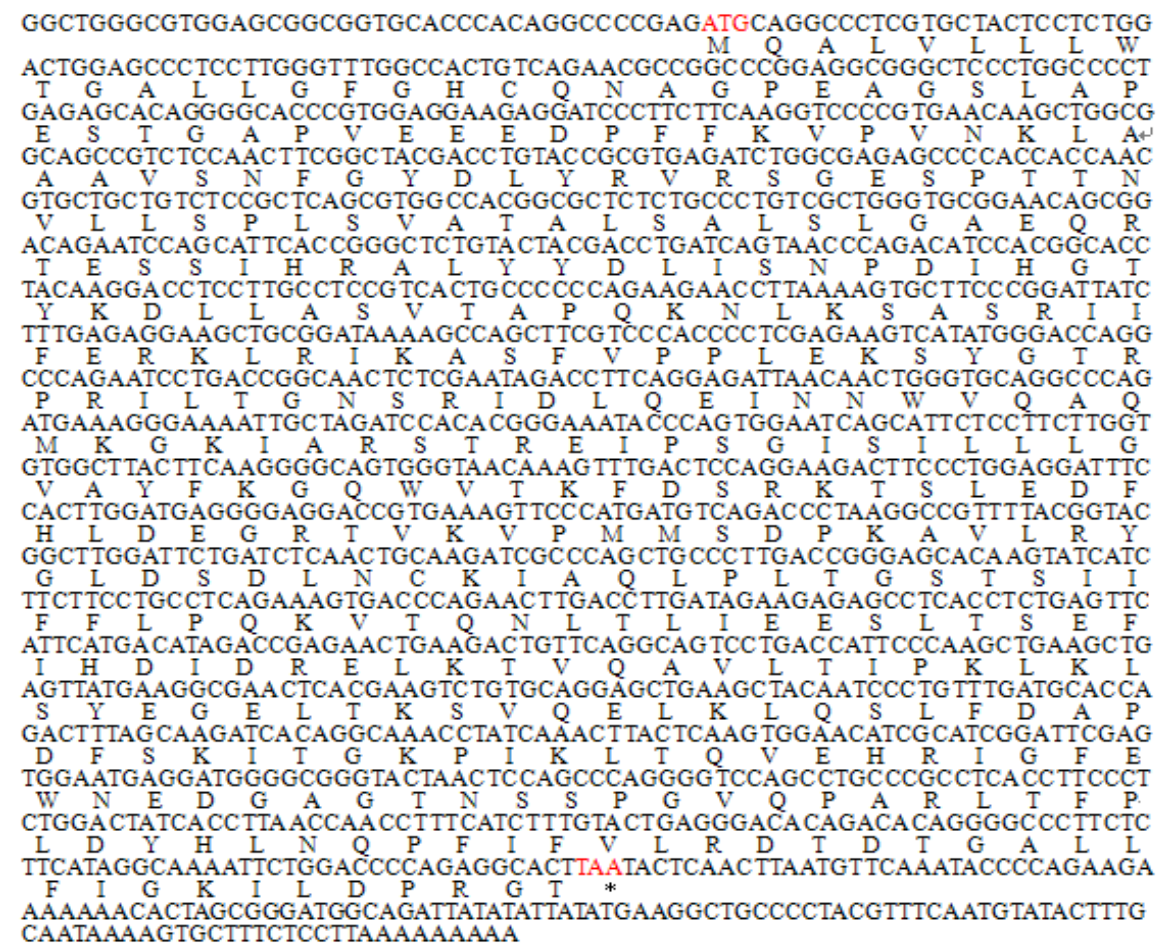

Fig. 2: The complete cDNA sequence and encoded amino acids of sheep SERPINF1 gene (GenBank accession number: FJ211198). ATG, start codon; TAA, stop codon. *indicates the stop codon

Mouse
Rat
Sheep
Bovine
Pig
Horse
Chimpanzee
Human
Crab-eating macaque
Dog
Domestic guinea pig
Red jungle fowl
Western clawed frog

Mouse
Rat
Sheep
Bovine
Pig
Horse
Chimpanzee
Human
Crab-eating macaque
Dog
Domestic guinea pig
Red jungle fowl
Western clawed frog
Mouse
Rat
Sheep
Bovine
Pig
Horse
Chimpanzee
Human
Crab-eating macaque

Fig. 3: Continue

\begin{abstract}
MQALVLLLUTGALLLGHGSSQNVPSSSEGSPVPDSTGE PVEEED-PFFKVVVKLAAAVSN MQTLVL L LUTGALLGHGSSQNVPDSSQDSPAPDSTGE PVVEDD P FFKAPVNKLAAAVSN MOALVLLLUTGALLGFGHCON--AGPEAGSLAPESTGAPVEEEDPFFKVPVNKLAAAVSN MQALVLLLWTGALLGFGRCQN--AGQEAGSLTPESTGAPVEEED PFFKVPVNKLAAAVSN MQALVLLLWTGALLGSGSCQN--AGPEEGSPAPDTVGAPVEEED PFFKVPVNKLAAAVSN MQALML L LUTGAL LGHGSCQMNAGGPEEGSPD PDITGÄPVEEED PFLKVPVNKLAAAVSN MOALVLLLCIGALLGHSSCONPASPPEEGSPDPDSTGALVEEEDPFFKVPVNKLAAAVSN MOALVLLLCIGALLGHSSCQNPASP PEEGSPDPDSTGALVEEEDPFFKVPVNKLAAAVSN MQALVLFLCFAALLGHSSCQSLASGPEEGSPD PDSTGALVEEED PFFKVPVNKLAAAAVSN ---------------MRAAPKD SPAPDATGVPVEEED PFFRVPVNKLAAAISN MOVLVLLLWTGALL LRGSCQDIASNPED-SPSPESTGE PVEEED PFFKVPVNKLAAAISN MQIPAVLLLLGLLTIPSKSQN--SPAGQNSPTTDGTVGEVEEED PFYKTP INKLAAAVSN MKIYLAL L FTGSFLSYTSAQN------AADEVPTEVEEED PFYKSPINRLASSASN
\end{abstract}

FGYDLYRLRSSASPTGNVLLSP LSVÄTALSALSLGÄEHRTESVIHRAL YYDLITNPDIHS FGYDL YRLRSGAVSTGNILLSP LSVATALSALSLGAEQRTESVIHRAL YYDL IMNPD IHS FGYD L YRVRSGE SPTTWVLLSP LSVATALSALSLGAEQRTE SS IHRALYYD L ISNPD IHG FGYD LYRVRSGE SPTANVL LSP LSVATAL SALS L GAEQRTE SNIHRAL YYD L ISNPD IHG FGYD L YRVRSSE SPTANVLLSP LSVATALSALSLGAEQRTE SS LHRAL YYDL ISNPDLHG FGYDL YRAKSSMS PTANVL LSP LSVATALSALSLGAEQRTE S IHLAL YYD L IKNPD IHG FGYDL YRVRS SMSPTTNVLLSP LSVATALSALSLGAEQRTESIIHRALYYDL ISSPD IHG FGYD L YRVRSSMS PTTNVL LS P LSVATALSALS L GAEQRTESI IHRAL YYD LISSPD IHG FGYD LYRVRSSMSPTTWVL LSP LSVATALSALSLGAEQRTESVIHRAL YYDLISSPDIHG FGYD L YRVRSS FS PAANVLLSP LSVATALSALSLGAEQRTESTIHRAL YYD L ISNPD IHS FGYD L YRVRSIE SPTTNVLLSP LSVATALSALSLGAEQRTEATIHRAL YYDMISNPDIHS FGYD LYRQQSSRTATANVL LS P FSLATALSGLS L GAGERTEDVISRAL FYD L LNKAEVHN FGYD L YRMQANRN PNSNIIISP LSIATS LS LSLGGGQRTE S L IQRS LYYD L LND PEVHA

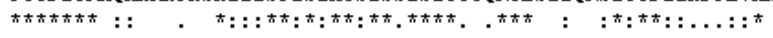
TYKE LLASVTAPEKNLKSASRIVFERKLRVKSS FVAPLEKSYGTRPRILTGNPRVDLQEI TYKE L LASVTAPEKNFKSASRIVFERKLRVKS FVAPLEKSYGTRPRILTGNPRIDLQEI TYKD L LASVTAPQKNLKSASRI I FERKLRIKAS FVP P LEKSYGTRPRI LTGNSRID LQEI TYKD L LASVTAPQKNLKSASRI I FERKLRIKASFIP P LEKSYGTRPRILTGNSRVD LQEI TYKE L LAAVTAPQKNLKSASRI I FEKKLRIKAS FVAP LEKSYGTRPRI LTGNSRLD LQEV TYKE L LASVTA PNKNFKSASRI I FEKKLRIKSS FVAP LEKSYGTRPKILTGNSRTD LQEI TYKE L LDTVTA PQKNLKSASRIVFEKKLRIKS S FVA PLEKSYGTRPRVLTGNPRLD LQEI TYKELLDTVTAPQKNLKSASRIVFEKKLRIKSS FVAP LEKSYGTRPRVLTGNPRLD LQEI TYKE LLGTVTAPQKNLKSASRIVFEKKLRIKSS FVAPLEKSYGTRPRVLTGNPRLDLQEI 


\section{J. Anim. Vet. Adv., 10 (19): 2593-2598, 2011}

Dog

Domestic guinea pig

Red jungle fowl

Western clawed frog

Mouse

Rat

sheep

Bovine

Pig

Horse

Chimpanzee

Human

Crab-eating macaque

Dog

Domestic guinea pig

Red jungle fowl

Western clawed frog

Mouse

Rat

Sheep

Bovine

Pig

Horse

Chimpanzee

Human

Crab-eating macaque

Dog

Domestic guinea pig

Red jungle fowl

Western clawed frog

Mouse
Rat
Sheep
Bovine
Pig
Horse
Chimpanzee
Human
Crab-eating macaque
Dog
Domestic guinea pig
Red jungle fowl
Western clawed frog
Mouse
Rat
Sheep
Bovine
Pig
Horse
Chimpanzee
Human
Crab-eating macaque
Dog
Domestic guinea pig
Red jungle fowl
Western

Western clawed frog

Mouse

Rat

sheep

Bovine

Pig

Horse

Chimpanzee

Human

Crab-eating macaque

Dog

Domestic guinea pig

Red jungle fowl

Western clawed frog
TYKE L LÅSVTẢPEKNFKSÅSRIVFERKLLIKSS FVAP LEKSYSTRPRILTGNPRLD LQEV TYKELLATVTAPOKNLKSASRIVFERKLRIKSSLVALLEKSYSTRPRILTGNPRIDLOEI TYKDL LASVTGPEKS LKSASRRI IVEKRLRVKSTFHSQLEKSYRMRLRALSGNTQLDLQEI TYKD L LASSFTSQASSGLKSTURIMLERRLRLRMD FVTQVEKFYGNKPKVLTGSTRLD LQEA

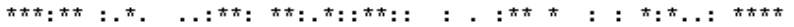

MNTVYOAOMKGKIARSTREMP SÄL SILLLGVAY FKGQTVTKFD SRKTTLOD FHLDEDRTVR NNTWOAOMKGKIARSTREMPSALSIL L LGVAYFKGQWATKFDSRKTTLQD FHLDEDRTVR MNTVQAOMKGKIARSTRE I P SGISI L L L GVAY FKGQWVTKFD SRKTS LED FHLDEGRTVK MNTVQA OMKGKVARSTREMPSE I I I L L GVAY FKGQWVTKFD SRKT S LED FYLDEERTVK NNTVQAQTKGKVARSTRE L P GE IS I L L LGVAY FKGQWVTKFD SRKTS LED FHLDEERTVK NNIWOAOMKGKIARSTREVP SE I S I L L L GVAYFKGQWVTKFD SRKTS LQD FHLDEERTVT MNTWQA AMKGKLARSTKE I PDE I I I L L L GVAHFKGQWVTKFDSRKTS LED FHLDEERTVR NNWVOAONKGKLARSTKE I PDE I S I L L L GVAHFKGQWVTKFD SRKTS LED FYLDEERTVR NNWVQA OMKGKLAR STKE L PDE I I I L L L GVAY FKGQWVTKFD PRKT LED FHLDEERTVR NNWVQAQMKGKIARSTRE I PSGIS I L L LGVAYFKGQWVTKFDSRKTS LED FHLDEERTVK SNWVOAOMKGKITRSTREVP SGISI L L L GVAYFKGQWVTKFD SRKTS LQD FHLDEERTVK NNITVQQTRGRI LRFMKDMPTDVSI L LAGAAY FKGTUKTKFD TKRTVLKD FHLDEDRTVO NDFIQKQTQGKVVFFKE I PTSVS I L L GTTYLKGQWAYKFNPRETVQRE FHLDEQTSVT

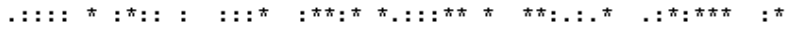

VPMMSD PKAILRYGLDSD LNCKIAQL P LTGSMSI IFFL PLTVTQNLTMIEESLTSE FIHD VPMMSD PKA ILRYGLDSD LNCKIAOL P LTGSMSI IFFL P LTVTONLTMIEE SLTSE FVHD VPMMSD PKAVLRYGLD SDLNCKIAQLPLTGSTSIIFFL PQKVTQNLTL IEESLTSE FIHD VPMMSD PQAVLRYGLDSD LNCKIAQL P LTGSTSIIFFL PQKVTQNLTLIEE SLTSE FIHD VPMMSD PKAVLRYGLDSD LNCKIAQLP LTGSMS I IFFL PLKVTQNLTMIEE SLTSE FIHD VPTMSD PKAILRYGLDSDLNCKIAOL PLTGSMSIVFFL PQKVTONLTMIEESLTSE FLHD VPMMSD PKAVLRYGLD SDLSCKIAQLPLTGSTSI IFFL P LKVTQNLTL IEE SLTSE FIHD VPMMSD PKAVLRYGLDSD L SCKIAQLP LTGSMSIIFFL P LKVTQNLTLIEE SLTSE FIHD VPMMSD PKAILRYGLDSD LSCKIAQL P LTGSMS I IFFL P LKVTQNLTL IEE S LTSEFIHD VPMMSD PKAILRYGLDSD L SCKIAQL P LTGSMS I IFFL P LKVTQNLTMIEES LTSE FIHD VPMMSD PKAIIRYGLDTD LNCKIAQL P LTGSMSI IFFL PMRÄTQNLTMIEE S LTSE FVHD VSMMSD PKA I LRYGFD SE LNCKIAQL P LTE GVSAMFFL PTKVTQMMTL IEES LTSE FVHD VPMMS SKNI PVRYGLDSD FNCKIVQL P LTGGVS IMFFL PNTVTQNLTMIEEGLTSE FVHD

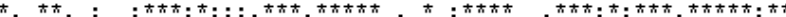

IDRE LKTIQAVLTVPKLKLSFEGE LTKSLQDMKLQSLFESPDFSKITGKPVKLTQVEHRA IDRE LKTIQAVLTVPKLKLSYE GDVTNS LQDMKLQSL FESPDFSKITGKPVKLTQVEHRA IDRE LKTVQAVLTI PKLKLSYE GE LTKSVQE LKLQSL FDA PDFSKITGKP IKLTQVEHRI IDRE LKTVQAVLTIPKLKLSYE GELTKSVQE LKLQSL FDAPDFSKITGKP IKLTQVEHRV IDRE LKTVQAVLTVPKLKL SYE GE LTKSVQE LKLQSL FD S PD FSKITGKP IKLTQVEHRI IDRE LKTVQAVLTI PKLKLSYE GEVTKS LQE IKLQSL FDSPDFSKITGKP LKLTQVEHRA IDRE LKTVQAVLTVPKLKLSYE GEVTKS LQEMKLQSL FDS PD FSKITGKP IKLTQVEHRA IDRE LKTVQAVLTVPKLKLSYE GEVTKSLQEMKL QSL FDSPD FSKITGKP IKLTQVEHRA IDRE LKTVQAVLTL PKLKL SYE GEVTKS LQETKLQSL FD SPDFSKITGKP IKLTQVEHRA IDRE LKTIQAVLTI PKLKLSYE GEVTKS LQEMKLQSL FD SPD FSKITGKP IKLTQVEHRA INRE LKAVQAVL S I PRLKL S FE GE LTKS LQEMKLHS L FE S PDFSKITGKP IKLTQVEHRA VDRE LKTVHAVL SL PKLKLNYEEALGNTVKETRL QSL FTS PD FTKISAKP IKLSHVQHKA IDQALQP INLVL SVPKLKLNYEAE LKEALQESKLQSLFATPDFSKISSKP LKL SYVWHKA

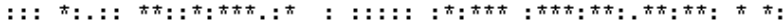
AFEUNNEEGAGSSPS-PGLQPVRLTFP LDYHLNQP FL FVLRDTDTGALLFIGRILDPSSTAFEWNEE GAGTSSN-PDLQPVRLTFP LDYHLNRP FI FVLRDTDTGALLFIGRILDPSSTGFEWNEDGAGTNSS-PGVQPARLTFP LDYHLNQPFI FVLRDTD TGAL L FIGKILDPRGTGFEUNEDGAGTNSS-PGVQPARLTFP LDYHLNQP FI FVLRDTDTGAL LFIGKI LDPRGTGFEUNEDGGSATSS-PGPR---LTFP LDYHLNQP FI FVLRDTDTGALL FIGKI LDPRSTGFEWNEDG-ATNPS-QGPQPAHLTFP LDYHLNQP FI FVLRDTDTGAL L FIGKILD PRGTGFETRTDGAGTTPS-PGLOPAHLTFPLDYHLNOPFIFVLRDTDTGALLFIGKILDPRGTGFEWNED GAGTTPS-PGLQPAHLTFP LDYHLNQP FI FVLRDTDTGAL L FIGKI LD PRGP-
GFEWNED GAGATPS-PGLQPAHLTFL LDYHLNQP FI FVLRDTDTGAL LIGKILD PRGTGFEWNED GAGTTPS-PGLQPTRLTFP LDYHLNRP FI FVLRDTDTGAL L FIGKILD PRGIGFEUNEE GAPGTSTNSD LQPTGFTFS LDYHLNQPFIFVLRDTDTGAL LFIGKILD PRSTVLELNEDGEKSTPN-PGVNAARLTFP IEYHVDRP FL LVLRDDTTGTL L FIGKILDPRSVTLE LNEE GAETAPK--PED SHRNYFP LEYHLDHP FL FVLRANDNGAL L FI GKVMD PKGF

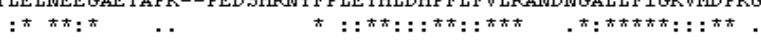

-

Fig. 3: The alignment of the protein encoded by sheep SERPINF1 gene and twelve other kinds of SERPINF1 proteins from bovine, pig, human, chimpanzee, horse, crab-eating macaque, dog, domestic guinea pig, mouse, rat, red jungle fowl and western clawed frog 


\section{J. Anim. Vet. Adv., 10 (19): 2593-2598, 2011}

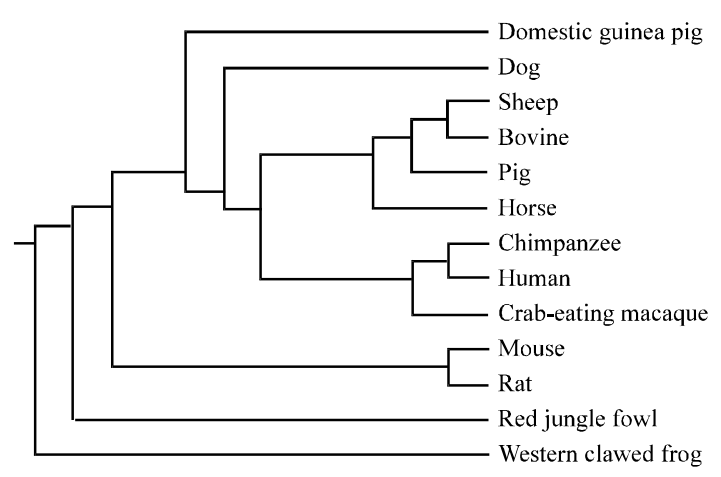

Fig. 4: The phylogenetic analysis for thirty kinds of SERPINF1 from sheep, bovine, pig, human, chimpanzee, horse, crab-eating macaque, dog, domestic guinea pig, mouse, rat, red jungle fowl and western clawed frog

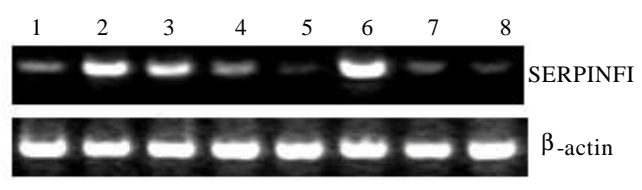

Fig. 5: Tissue expression profile analysis of the sheep SERPINF 1 gene on the agarose gel of $1 \%$ stained with ethidium bromide. The $\beta$-actin expression is the control. M, DL2000 marker; 1, spleen; 2, muscle; 3 , skin; 4 , kidney; 5 , lung; 6 , liver; 7 , heart; 8 , fat

From the sequencing and structural results described, this gene can be defined as the sheep SERPINF1 gene. Based on the results of the alignment of thirty different species of SERPINF1, a phylogenetic tree was constructed using the ClustalW software (http://www. ebi.ac.uk/clustalw) as shown in Fig. 4. The phylogenetic analysis revealed that the sheep SERPINF1 gene has a closer genetic relationship with the bovine SERPINF1 gene than with those of pig, human, chimpanzee, horse, crab-eating macaque, dog, domestic guinea pig, mouse, rat, red jungle fowl and western clawed frog.

Tissue expression profile: The RT-PCR analysis of the tissue expression profile was carried out using the pooled tissue cDNAs as the templates. The tissue expression analysis indicated that the sheep SERPINF1 gene is highly expressed in muscle and liver and moderately expressed in skin but weakly expressed in spleen, kidney, lung, heart and fat (Fig. 5).

In the current study, we firstly get the full length of sheep SERPINF1 gene cDNA by using 5'- and 3'-RACE. With the development of modern bioinformatics and specific sheep NCBI EST database was established along with different convenient analysis tools make researchers much easier to find the useful ESTs which was highly homologous to the coding sequence of human genes. Based on these sheep EST sequences, the researchers can obtain the complete coding sequences of some novel sheep genes through the some modern experimental methods such as Rapid Amplification of cDNA Ends (RACE) method. From the clone and sequence analysis of sheep SERPINF1 gene, it could be seen that this is an effective method to isolate some novel pig genes.

Through sequence analysis, we found that the encoding protein of the sheep SERPINF1 gene is highly homologous with SERPINF1 proteins of human, mouse and other mammals. This implied that the SERPINF1 genes were highly conserved in some mammals and the sheep SERPINF1 gene will have similar functions as the SERPINF1 genes of human, mouse and other mammals. The researchers also found that the sheep SERPINF1 protein does not show complete identity to human, mouse or other mammals. This implied that the sheep SERPINF1 gene will have some differences in functions to those of human, mouse or other mammals. From phylogenetic analysis we found that sheep SERPINF1 gene has a closer genetic relationship with the SERPINF1 gene of bovine, this implied that we can use bovine as a model organism to study the sheep SERPINF1 gene.

From the tissue distribution analysis in the experiment it can be seen that the sheep SERPINF1 gene was obviously differentially expressed in some tissues. As we did not study functions at protein levels yet there might be many possible reasons for differential expression of sheep SERPINF1 gene. The suitable explanation for this under current conditions is that at the same time those biological activities related to the mRNA expression of sheep SERPINF1 gene were presented diversely in different tissues.

\section{CONCLUSION}

In this study, the researchers first isolated the sheep SERPINF1 gene and performed necessary sequence analysis and tissue transcription profile analysis. This established the primary foundation for further insight into this novel sheep gene.

\section{REFERENCES}

Becerra, S.P., I. Palmer, A. Kumar, F. Steele, J. Shiloach, V. Notario and G.J. Chader, 1993. Overexpression of fetal human pigment epithelium-derived factor in Escherichia coli. A functionally active neurotrophic factor. J. Biol. Chem., 268: 23148-23156. 
Chen, C., A.W. Tso, L.S. Law, B.M. Cheung and K.L. Ong et al., 2010. Plasma level of pigment epithelium-derived factor is independently associated with the development of the metabolic syndrome in Chinese men: A 10-year prospective study. J. Clin. Endocrinol. Metab., 95: 5074-5081.

Gvritishvili, A.G., K.W. Leung and J. Tombran-Tink, 2010. Codon preference optimization increases heterologous PEDF expression. PloS One, 5: 15056-15056.

Ho, T.C., S.L. Chen, S.C. Shih, J.Y. Wu and W.H. Han et al., 2010. Pigment epithelium-derived factor is an intrinsic antifibrosis factor targeting hepatic stellate cells. Am. J. Pathol., 177: 1798-1811.

Konson, A., S. Pradeep, C.W. D'Acunto and R. Seger, 2011. Pigment epithelium-derived factor and its phosphomimetic mutant induce JNK-dependent apoptosis and p38-mediated migration arrest. J. Biol. Chem., 286: 3540-3551.

Liu, G.Y. and S.Z. Gao, 2009. Molecular cloning, sequence identification and tissue expression profile of three novel sheep (Ovis aries) genes-BCKDHA, NAGA and HEXA. Biol. Res., 42: 69-77.
Liu, G.Y., 2009. A novel HADHA gene differentially expressed in muscle and other tissues from blackboned vs. ordinary sheep. Anim. Sci. Pap. Rep., 27: $127-137$.

Pignolo, R.J., V.J. Cristofalo and M.O. Rotenberg, 1993. Senescent WI-38 cells fail to express EPC-1, a gene induced in young cells upon entry into the G0 state. J. Biol. Chem., 268: 8949-8957.

Simonovic, M., P.G. Gettins and K. Volz, 2001. Crystal structure of human PEDF, a potent anti-angiogenic and neurite growth-promoting factor. Proc. Natl. Acad. Sci. USA., 98: 11131-11135.

Wagsater, D., S. Lofgren, N. Zar, A. Hugander and J. Dimberg, 2010. Pigment epithelium-derived factor expression in colorectal cancer patients. Cancer Invest., 28: 872-877.

Yonggang, June 24, 2011L. and G. Shizheng, 2009. A novel sheep gene, MMP7, differentially expressed in muscles from black-boned sheep and local common sheep. J. Applied Genet., 50: 253-256. 